\title{
Effects of Magnesium Impregnation on Stability and Sorption Performance of Biochar Derived from Sawdust and Corn Husks
}

\begin{abstract}
Zhao Xu, ${ }^{\mathrm{a}}$ Ting Chen, ${ }^{\mathrm{a}}$ Zhuhong Ding, ${ }^{\mathrm{a}, *} \mathrm{Xin} \mathrm{Hu},{ }^{\mathrm{b}}$ and Guangze $\mathrm{Nie}^{\mathrm{a}}$
Biochar was derived from $\mathrm{MgCl}_{2}$ and $\mathrm{MgO}$ pretreated sawdust and corn husks at $300{ }^{\circ} \mathrm{C}$ and $600{ }^{\circ} \mathrm{C}$, respectively, to investigate the effects of exogenous minerals on the stability and sorption performance of the resulting biochar. Impregnation with $\mathrm{Mg}$ decreased carbon concentration, increased yield and ash concentration, and increased the $\mathrm{pH}$ values at the point of zero charge ( $\mathrm{pH}$ PzC) of the resulting biochar. The chemical stability of biochar oxidized by $\mathrm{K}_{2} \mathrm{CrO}_{7}$ was enhanced with increasing pyrolysis temperature and decreased with the pretreatment of $\mathrm{MgCl}_{2}$ and $\mathrm{MgO}$. $\mathrm{Mg}$ impregnation enhanced carbon loss of the resulting biochar and increased the sorption capacity of biochar for CR significantly, which is potentially caused by electrostatic interaction and surface complexation. This study indicates that magnesium-impregnation significantly enhances the sorption performance of anionic contaminants and the pyrolysis temperature has a greater effect on the stability of the resulting biochar than the magnesium-impregnation.
\end{abstract}

Keywords: Mineral additive; Pyrolysis temperature; Physicochemical property; Stability; Batch sorption

Contact information: a: School of Environmental Science \& Engineering, Nanjing Tech University, 30 Puzhu Southern Road, Nanjing 211816, P.R. China; b: State Key Laboratory of Analytical Chemistry for Life Science, Center of Material Analysis and School of Chemistry and Chemical Engineering, 22 Hankou Road, Nanjing University, Nanjing 210093, P.R. China;

* Corresponding author: dzhuhong@njtech.edu.cn

\section{INTRODUCTION}

Biochar is generally produced through the slow pyrolysis of biomass feedstock under oxygen-limited conditions. Biochar has excellent potential in carbon sequestration, improvement of soil fertility, environmental remediation/restoration, and wastewater treatment (Xie et al. 2016; Inyang et al. 2016). The stability and sorption performance of biochar are important parameters for their application in carbon sequestration, soil remediation, and wastewater treatment, which are dependent on the physicochemical properties of biochar. Chen et al. (2016) report that the chemical oxidation stability of bamboo biochar is improved with increasing pyrolysis temperature between $300{ }^{\circ} \mathrm{C}$ and $700{ }^{\circ} \mathrm{C}$. Singh et al. (2012) found that the plant-based biochar was more stable than manure-based biochar. Mineral elements play an important role in the stability and sorption performance of biochar. For example, minerals have a greater influence than organic components on the surface electrochemistry and ion exchange properties of plant-based and municipal waste-based biochar derived from twelve types of biomass feedstock (Zhao et al. 2015). To obtain biochar with more abundant minerals, exogenous minerals have been added to design engineered biochar (Xie et al. 2016). For example, Xu et al. (2017) reports $\mathrm{CaCO}_{3}$ and $\mathrm{Ca}\left(\mathrm{H}_{2} \mathrm{PO}_{4}\right)_{2}$ as additives enhance the stability of sewage sludge biochar. Hu et al. (2015) demonstrate that a pretreatment of biomasses with metal salts (e.g., 
magnesium salts, iron salts, and aluminum salts) effectively improve the adsorption capacities of the resulting biochar (Hu et al. 2015).

Magnesium hydroxides are cheaper, more environmentally-friendly adsorbents due to their higher isoelectric points (IEP), which range from 10.8 to 12 for $\mathrm{Mg}(\mathrm{OH})_{2}$ and from 9.8 to 12 for anhydrous oxide (Kosmulski 2016). Recent literature shows that Mgimpregnated biochar significantly improves the sorption capability for phosphate and nitrate (Inyang et al. 2016; Xie et al. 2016). $\mathrm{MgCl}_{2}$ is generally used as an additive due to its easy hydrolysis and decomposition when heated. The main reactions are as follows ( $\mathrm{Li}$ et al. 1987):

$$
\begin{aligned}
& \mathrm{MgCl}_{2}+2 \mathrm{H}_{2} \mathrm{O} \leftrightharpoons \mathrm{Mg}(\mathrm{OH})_{2}+2 \mathrm{HCl} \uparrow \\
& \mathrm{MgCl}_{2}+2 \mathrm{H}_{2} \mathrm{O} \triangleq \mathrm{MgOHCl}+\mathrm{HCl} \uparrow+\mathrm{H}_{2} \mathrm{O}\left(250 \text { to } 450{ }^{\circ} \mathrm{C}\right) \\
& \mathrm{Mg}(\mathrm{OH})_{2} \rightarrow \mathrm{MgO}+\mathrm{H}_{2} \mathrm{O}\left(350{ }^{\circ} \mathrm{C}\right) \\
& \mathrm{MgOHCl} \triangleq \mathrm{MgO}+\mathrm{HCl} \uparrow\left(>450{ }^{\circ} \mathrm{C}\right)
\end{aligned}
$$

The hydrolysis and decomposition of $\mathrm{MgCl}_{2}$ in the $\mathrm{MgCl}_{2}$-pretreated biomass under different pyrolysis temperature result in $\mathrm{MgO}, \mathrm{Mg}(\mathrm{OH})_{2}$, and $\mathrm{Mg}$ salts, which may modify the physicochemical properties of the resulting biochar.

In this study, sawdust and corn husks were pretreated with either $\mathrm{MgCl}_{2}$ or $\mathrm{MgO}$. The Mg-impregnated biochar specimens were prepared at a pyrolysis temperature between $300{ }^{\circ} \mathrm{C}$ and $600{ }^{\circ} \mathrm{C}$. The objectives of this study were: (1) to investigate the release of dissolved organic carbon and $\mathrm{Mg}$ from biochar; and (2) to evaluate the chemical stability of carbon in biochar using $\mathrm{K}_{2} \mathrm{CrO}_{7}$ oxidation, and the sorption performance through batch sorption of methylene blue (MB) and Congo red (CR).

\section{EXPERIMENTAL}

\section{Preparation of Biochar}

The sawdust and corn husks were collected from a local sawmill and a grain processing factory in Nanjing, China. They were washed and then crushed into samples smaller than $1 \mathrm{~mm}$, and finally they were soaked in either $\mathrm{MgCl}_{2}$ or $\mathrm{MgO}$ solution (mass ratios of $\mathrm{Mg}$ to biomass $=1: 10$ ). Subsequently, the supernatant was removed after $24 \mathrm{~h}$, and mixtures were dried at $85^{\circ} \mathrm{C}$ for $24 \mathrm{~h}$. The sawdust biochar (SB) and corn husk biochar (CB) were pyrolyzed in a tube furnace (OTF-1200X, HF-Kejing, Hefei, China) under a nitrogen atmosphere and marked as SB3 and CB3 or SB6 and CB6 corresponding to the pyrolysis temperatures of $300{ }^{\circ} \mathrm{C}$ for $4 \mathrm{~h}$, and $600{ }^{\circ} \mathrm{C}$ for $2 \mathrm{~h}$, respectively. Sawdust and corn husks pre-treated with $\mathrm{MgCl}_{2}(\mathrm{MC})$ and $\mathrm{MgO}(\mathrm{MO})$ were also pyrolyzed following same condition and the resulting biochars were marked as MC/SB3 and MC/CB3, MC/SB6 and $\mathrm{MC} / \mathrm{CB} 6, \mathrm{MO} / \mathrm{SB} 6$, and MO/CB6.

\section{Characterization of Biochar}

Biochar yield was calculated using the mass ratios of the resulting biochar to biomass feedstock. The ash content of the resulting biochar was measured by ashing biochar in a muffle furnace at $550{ }^{\circ} \mathrm{C}$ for $5 \mathrm{~h}$. The content of carbon $(\mathrm{C})$, hydrogen $(\mathrm{H})$, and nitrogen (N) of biochar were measured using an Elemental Analyzer (Carlo-Erba NA-1500, Hanau, Germany). The $\mathrm{pH}$ value at the point of zero charge ( $\mathrm{pH}_{\mathrm{PZC}}$ ) of the biochar was determined using the impregnated $\mathrm{pH}$ drift method. The functional groups of the biochar were 
characterized using a Fourier Transform Infrared Spectrometer (NEXUS870, NICOLET, Boston, MA, USA). The crystallographic structures of the biochar were determined using an X-ray Diffractometer (CAD4/PC, Enraf Noius, NED, Geneva, Switzerland). The thermal stability of the biochar was analyzed using a Thermogravimetric (TG) analyzer (DTA449F3, NETZSCH, Selb, Germany) under a nitrogen atmosphere and heated to temperatures between 25 and $700{ }^{\circ} \mathrm{C}$.

\section{Release Kinetics of Dissolved Organic Carbon and Mg from Biochar}

One $\mathrm{g}$ of biochar, derived under $300{ }^{\circ} \mathrm{C}$, was added to $50 \mathrm{~mL}$ of deionized (DI) water in a $50 \mathrm{~mL}$ centrifuge tube and shaken at $25^{\circ} \mathrm{C}$ for five different time intervals $(1,2$, 4,8 , and $24 \mathrm{~h}$ ). The centrifuge separated the solid and liquid phases, which were then filtered through a $0.22 \mu \mathrm{m}$ membrane. The dissolved organic carbon (DOC) in the filtrate was analyzed using a total carbon analyzer (TOC-L/CPH, SHIMADZU, Kyoto, Japan) and the releasable $\mathrm{Mg}$ in the filtrate of the $24 \mathrm{~h}$ extraction was analyzed by an inductively coupled plasma optical emission spectrometer (ICP-OES) (Optima 5300, PerkinElmer, Waltham, MA, USA).

\section{Chemical Oxidation of Carbon}

To determine the chemical stability of biochar, potassium dichromate $\left(\mathrm{K}_{2} \mathrm{Cr}_{2} \mathrm{O}_{7}\right)$ is used to assess the labile fraction of carbon (C) (Xu et al. 2017). A sample of $0.1 \mathrm{~g}$ of biochar was placed into a glass bottle with $40 \mathrm{~mL}$ of $0.1 \mathrm{M} \mathrm{K}_{2} \mathrm{Cr}_{2} \mathrm{O}_{7}$ and $2 \mathrm{M} \mathrm{H}_{2} \mathrm{SO}_{4}$ solution, and then heated in a water bath at $55^{\circ} \mathrm{C}$ for $60 \mathrm{~h}$. The concentration of $\mathrm{C}$ in the biochar after oxidation was measured by an Elemental Analyzer (Carlo-Erba NA-1500, Hanau, Germany). The $\mathrm{C}$ loss ratio of the biochar was calculated according to Eq. 5,

$$
W=\left(M_{0} \times N_{0}-M \times N\right) \times 100 /\left(M_{0} \times N_{0}\right)
$$

where $M_{0}$ and $M$ are the mass of biochar before and after the oxidation treatment $(\mathrm{mg})$, respectively, $N_{0}$ and $N(\%)$ are the carbon concentrations in the biochar before and after the oxidation treatment $(\%)$, respectively, and $W$ is the $\mathrm{C}$ loss ratio.

\section{Isothermal Adsorption for Methylene Blue and Congo Red}

Methylene blue (MB) and Congo red (CR) are common cationic and anionic dyes, respectively. The isothermal adsorptions of $\mathrm{MB}$ and $\mathrm{CR}$ onto biochar were performed to evaluate the sorption performance. According to preliminary experiments, the initial concentrations were set between 5 to $100 \mathrm{mg} \mathrm{L}^{-1}$ of $\mathrm{MB}$, from 5 to $100 \mathrm{mg} \mathrm{L}^{-1}$ of CR for CB3, CB6, SB3, SB6, and from 50 to $1000 \mathrm{mg} \mathrm{L}^{-1}$ of CR for MC/SB3, MC/SB6, MO/SB6, $\mathrm{MC} / \mathrm{CB} 3, \mathrm{MC} / \mathrm{CB} 6$, and $\mathrm{MO} / \mathrm{CB} 6$. The initial $\mathrm{pH}$ of the $\mathrm{MB}$ and $\mathrm{CR}$ solution was set to $7.0 \pm 0.2$ using a $\mathrm{pH}$ meter. A sample of $0.05 \mathrm{~g}$ of biochar was placed in a $50 \mathrm{~mL}$ centrifuge tube and then $25 \mathrm{~mL} \mathrm{MB}$ or CR solution with the designed concentration was added. The mixed solution was shaken at room temperature $\left(22 \pm 2{ }^{\circ} \mathrm{C}\right)$ for $24 \mathrm{~h}$. After centrifugation and filtration, the concentrations of $\mathrm{MB}$ and $\mathrm{CR}$ were detected via an ultraviolet spectrophotometer (PHILES, T-6, Nanjing, China) at $663 \mathrm{~nm}$ and $449 \mathrm{~nm}$, respectively. The amount of $\mathrm{MB}$ and $\mathrm{CR}$ absorbed was calculated using the following equations,

$$
Q_{\mathrm{e}}=\left(C_{0}-C_{\mathrm{e}}\right) \times V / \mathrm{m}
$$

where $q_{\mathrm{e}}$ is the equilibrium absorption capacity $(\mathrm{mg} / \mathrm{kg}), C_{\mathrm{o}}$ and $C_{\mathrm{e}}$ are the initial and equilibrium concentrations $(\mathrm{mg} / \mathrm{L}$ of $\mathrm{MB}$ and $\mathrm{CR}$, resprctively; $V$ is the volume of solution (L), and $m$ is the mass of biochar $(\mathrm{g})$. 


\section{RESULTS AND DISCUSSION}

\section{Effect of Mg Addition on the Basic Physicochemical Properties of Biochar}

Elemental compositions of the resulting biochar

Table 1 shows that the pyrolysis temperature had a significant effect on the elemental composition of the resulting biochar. An increase in the pyrolysis temperature resulted in the decrease in the concentration of $\mathrm{O}$ and $\mathrm{H}$, while the concentration of $\mathrm{C}$ and ash increased (Table 1). Additionally, Table 1 showed that the mineral addition played an important role on the elemental compositions of the resulting biochar. For example, $\mathrm{Mg}$ concentrations in the resulting biochar increased with the increased pyrolysis temperature (from $300{ }^{\circ} \mathrm{C}$ to $600{ }^{\circ} \mathrm{C}$ ) (Table 1). Biochar derived from the $\mathrm{MgCl}_{2}$-pretreated biomass feedstock had higher concentrations of ash and $\mathrm{O}$, with lower concentrations of $\mathrm{C}$ than those from origin biomass feedstock. Similar results were also observed for the pretreatment of $\mathrm{MgO}$ (Table 1). Concentrations of $\mathrm{N}$ were low, and they changed only a little among the resulting biochars (Table 1), which were reported that no nitrogencontaining substances were formed (Gaskin et al. 2008). The $\mathrm{H} / \mathrm{C}, \mathrm{O} / \mathrm{C}$, and $(\mathrm{O}+\mathrm{N}) / \mathrm{C}$ ratios indicated the aromaticity and polarity of biochar (Azargohar et al. 2013). With the increasing pyrolysis temperature, the $\mathrm{H} / \mathrm{C}, \mathrm{O} / \mathrm{C}$, and $(\mathrm{O}+\mathrm{N}) / \mathrm{C}$ obviously decreased (Table 1 ), which indicated that the aromaticity increased and polarity decreased at $600{ }^{\circ} \mathrm{C}$. The concentrations of ash for Mg-impregnated biochars were higher than that in the pristine biochar, which were consistent with the increasing $\mathrm{Mg}$ concentrations in the biochars (Table 1). However, the pretreatment of $\mathrm{MgCl}_{2}$ and $\mathrm{MgO}$ had different effects on element composition and yield of the resulting biochar (Table 1). The mineral elements, such as $\mathrm{K}$, $\mathrm{Ca}$, and $\mathrm{Na}$, were also found in the biochars at relatively low concentrations compared with other tested elements of biochars.

pHPZC of biochar

The $\mathrm{pH}_{\mathrm{PZC}}$ of the biochar was an important indicator of the surface charge of the adsorbent. The $\mathrm{pH}_{\mathrm{PZC}}$ of the studied biochar were in the order of MO/SB6 (10.6) > MC/SB6 (10.4) $>\mathrm{MC} / \mathrm{SB} 3(8.8)>\mathrm{SB} 6(8.5)>\mathrm{SB} 3$ (7.4) for sawdust-based biochar, and MO/CB6 $(10.4)=\mathrm{MC} / \mathrm{CB} 6(10.4)>\mathrm{MC} / \mathrm{CB} 3(9.5)>\mathrm{CB} 6(9.2)>\mathrm{CB} 3$ (7.7) for corn husk-based biochar. The values of $\mathrm{pH}$ PZC for the resulting biochar increased as the pyrolysis temperature increased from 300 to $600{ }^{\circ} \mathrm{C}$, and the values of $\mathrm{pH}$ PZC for the resulting $\mathrm{Mg}$ impregnated biochar were higher than that in the pristine biochar, suggesting that the pretreatment of $\mathrm{MgCl}_{2}$ and $\mathrm{MgO}$ increased the $\mathrm{pH}$ PzC of the resulting biochars. Therefore, all Mg-impregnated biochars showed surface positive charges in acid, neutral, and weak alkaline solutions, which is beneficial for the sorption of anionic contaminants.

\section{FT-IR and XRD spectra of biochar}

The FT-IR spectra of biochars are shown in Fig. 1(a). The peak at $3698 \mathrm{~cm}^{-1}$ in $\mathrm{MO} / \mathrm{SB} 6$ and MO/CB6 could be assigned to $\mathrm{Mg}-\mathrm{OH}$, but this peak was not observed in other biochars. The peak at $3390 \mathrm{~cm}^{-1}$ was suggested to be $-\mathrm{OH}$ and disappeared with the increasing pyrolysis temperature, which might be due to the decrease of $-\mathrm{OH}$. The peaks were assigned to $-\mathrm{CH}_{3}$ at $2900 \mathrm{~cm}^{-1}$, and $-\mathrm{COOH}$ at 1700 and $1600 \mathrm{~cm}^{-1}$ (Fig. 1(a)). The peak of $-\mathrm{COOH}$ became weak as the pyrolysis temperature increased, which indicated the reduction of the oxygen-containing functional groups. 
Table 1. Elemental Composition, Ash Concentration, and Yield of Each Biochar

\begin{tabular}{|c|c|c|c|c|c|c|c|c|c|c|c|c|c|}
\hline & \multicolumn{7}{|c|}{ Elemental Concentration $(\%)$} & $\begin{array}{c}\text { Ash } \\
(\%)\end{array}$ & $\begin{array}{c}\text { Yield } \\
(\%)\end{array}$ & O/C & H/C & $\begin{array}{c}\text { (O+N } \\
\text { /C }\end{array}$ \\
\hline SB3 & 73.6 & 5.90 & 19.0 & 0.01 & 0.09 & 0.47 & 0.31 & 0.09 & 1.49 & 30.2 & 0.19 & 0.96 & 0.19 \\
\hline SB6 & 89.2 & 2.15 & 6.21 & 0.06 & 0.11 & 0.59 & 0.42 & 0.11 & 2.38 & 21.5 & 0.05 & 0.29 & 0.05 \\
\hline MC/SB3 & 62.2 & 4.65 & 24.6 & 0.03 & 3.52 & 0.03 & 0.19 & 0.04 & 8.52 & 43.6 & 0.29 & 0.89 & 0.29 \\
\hline MC/SB6 & 79.1 & 2.36 & 6.01 & 0.03 & 5.58 & 0.19 & 0.12 & 0.17 & 12.5 & 33.8 & 0.06 & 0.36 & 0.06 \\
\hline MO/SB6 & 56.2 & 2.29 & 11.0 & 0.01 & 14.5 & 0.15 & 0.23 & 0.05 & 30.5 & 35.7 & 0.15 & 0.49 & 0.15 \\
\hline CB3 & 68.9 & 4.79 & 19.1 & 0.36 & 0.08 & 1.32 & 0.35 & 0.05 & 6.85 & 34.8 & 0.21 & 0.83 & 0.21 \\
\hline CB6 & 79.4 & 2.19 & 7.92 & 0.09 & 0.11 & 1.09 & 0.23 & 0.04 & 10.4 & 25.2 & 0.08 & 0.33 & 0.08 \\
\hline MC/CB3 & 58.3 & 4.29 & 26.4 & 0.21 & 2.75 & 0.11 & 0.08 & 0.04 & 10.8 & 38.4 & 0.34 & 0.88 & 0.34 \\
\hline MC/CB6 & 67.7 & 2.31 & 8.64 & 0.05 & 5.12 & 0.54 & 0.13 & 0.22 & 21.3 & 33.3 & 0.10 & 0.41 & 0.09 \\
\hline MO/CB6 & 42.4 & 1.79 & 24.4 & 0.11 & 11.5 & 0.25 & 0.11 & 0.06 & 31.3 & 37.6 & 0.43 & 0.51 & 0.43 \\
\hline
\end{tabular}

* Oxygen concentration (\%) was calculated by mass difference between total mass and tested elements/ash. 
The peaks in the 1400 and $880 \mathrm{~cm}^{-1}$ regions were assigned to aromatic $\mathrm{C}-\mathrm{O}$ and aromatic $\mathrm{C}-\mathrm{H}$ functional groups, respectively. The broadband in the 788 to $881 \mathrm{~cm}^{-1}$ region was related to the bond stretching vibrations of $-\mathrm{CH}_{2}$ and $\mathrm{C}=\mathrm{C}-\mathrm{H}$. There were no significant differences between the FT-IR spectra of the pristine sawdust-based bichars and that of the pristine corn husk-based biochars (Fig. 1(a)). The increasing pyrolysis temperature reduced surface functional groups and the addition of $\mathrm{Mg}$ had no significant changes on surface functional groups (Fig. 1(a)).

The XRD spectra of biochar is shown in Fig. 1(b). The peak of all biochars at 2 theta of $23^{\circ}$ was generally identified as the crystal structure of cellulose; however, there were no obvious peaks, which suggested that there was no crystalline cellulose in the resulting biochars. The peaks located at 2 theta of $37^{\circ}, 43^{\circ}$, and $62^{\circ}$ in $\mathrm{MC} / \mathrm{SB} 6, \mathrm{MO} / \mathrm{SB} 6$, $\mathrm{MC} / \mathrm{CB} 6$, and MC/CB6 were assigned to crystalline $\mathrm{MgO}$ (periclase) (Fig. 3), as stated in previous reports (Liu et al. 2013). The peaks at 2 theta of $18^{\circ}, 50^{\circ}$, and $58^{\circ}$ were identified as $\mathrm{Mg}(\mathrm{OH})_{2}$ in $\mathrm{MO} / \mathrm{CB} 6, \mathrm{MO} / \mathrm{SB} 6$, and MC/SB6 (Fig. 1(b)), as supported by previous reports ( $\mathrm{Xu}$ et al. 2018). No peaks were found in MC/CB3 and MC/SB3, which may be due to crystalline minerals in biochars below the detection limit of XRD or no crystalline minerals at $300{ }^{\circ} \mathrm{C}$ (Fig. 1(b)). Additionally, there were no crystalline minerals in the pristine biochars derived from feedstock without the pretreatment of $\mathrm{MgCl}_{2}$ and $\mathrm{MgO}$.
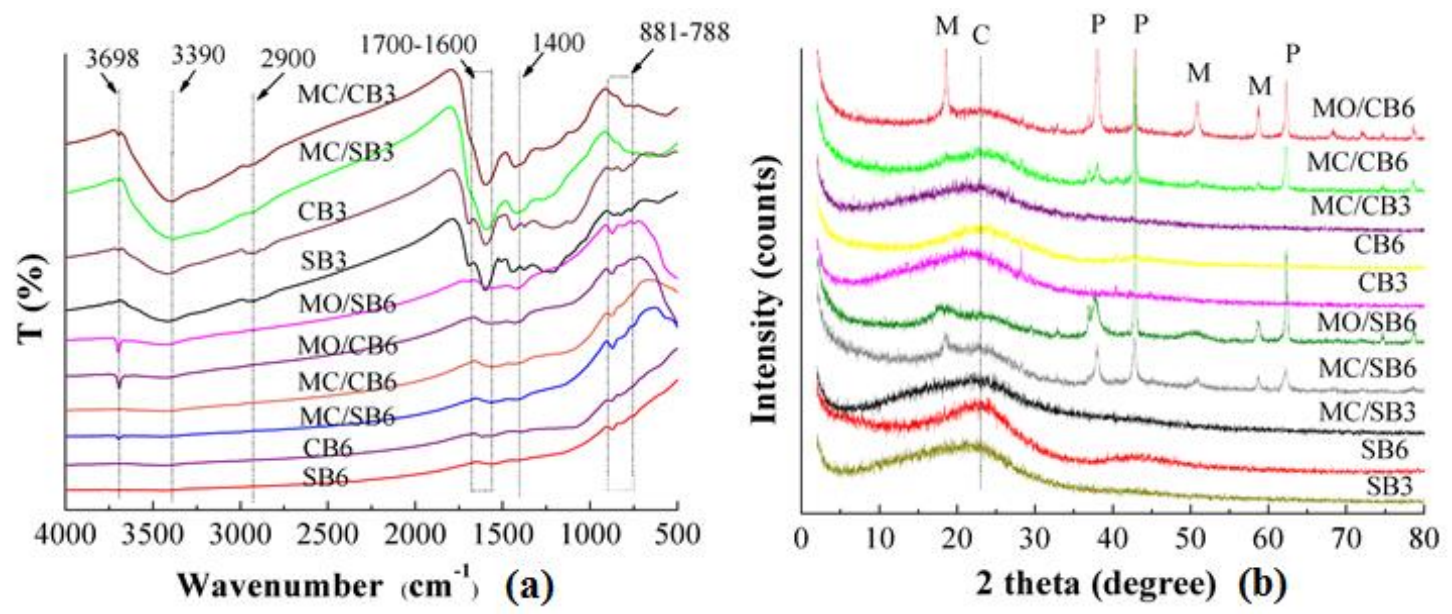

Fig. 1. Spectra of FT-IR (a) and XRD (b) (M, Mg(OH) $;$; , cellulose; $\mathrm{P}, \mathrm{MgO})$.

\section{Effect of Mg Addition on the Stability of the Resulting Biochar}

Release of DOC and $\mathrm{Mg}$ from biochar

The release kinetics during the 1 to $24 \mathrm{~h}$ of DOC from SB3, CB3, MC/SB3, and $\mathrm{MC} / \mathrm{CB} 3$ are presented in Fig. 2. The release of DOC arrived at an equilibrium within $4 \mathrm{~h}$. Therefore, the release of DOC from all studied biochar was set as $24 \mathrm{~h}$ time interval. The releasable concentrations of DOC from biochar $\left(\mathrm{mg} \mathrm{g}^{-1}\right)$ after the $24 \mathrm{~h}$ extraction were in the order of MC/SB3 (14.5)>MC/CB3 (9.66) > SB3 (1.84)>SS6 (0.63)>MC/SB6 (0.54) $>\mathrm{CB} 3(0.52)=\mathrm{MO} / \mathrm{SB} 6(0.52)>\mathrm{CB} 6(0.47)>\mathrm{MC} / \mathrm{CB} 6(0.41)>\mathrm{MO} / \mathrm{CB} 6(0.39)$. These results suggested that the releasable concentration of DOC in biochar decreased as the pyrolysis temperature was increased. The highest releasable concentration of DOC (14.5 $\mathrm{mg} \mathrm{g}^{-1}$ ) were found from MC/SB3, followed by $\mathrm{MC} / \mathrm{CB} 3$, indicating that the pretreatment of $\mathrm{MgCl}_{2}$ increased the release of DOC of biochar at the pyrolysis temperature of $300{ }^{\circ} \mathrm{C}$. The releasable concentrations of $\mathrm{Mg}$ after a $24 \mathrm{~h}$ extraction were $0.056,0.041,15.1,1.73$, $3.22,0.34,0.20,16.7,4.02$, and $3.35 \mathrm{mg} \mathrm{g}^{-1}$ for SB3, SB6, MC/SB3, MC/SB6, MO/SB6, 
CB3, CB6, MC/CB3, MC/CB6, and MO/CB6, respectively. These findings indicated that soluble $\mathrm{Mg}$ was present in the bichars.

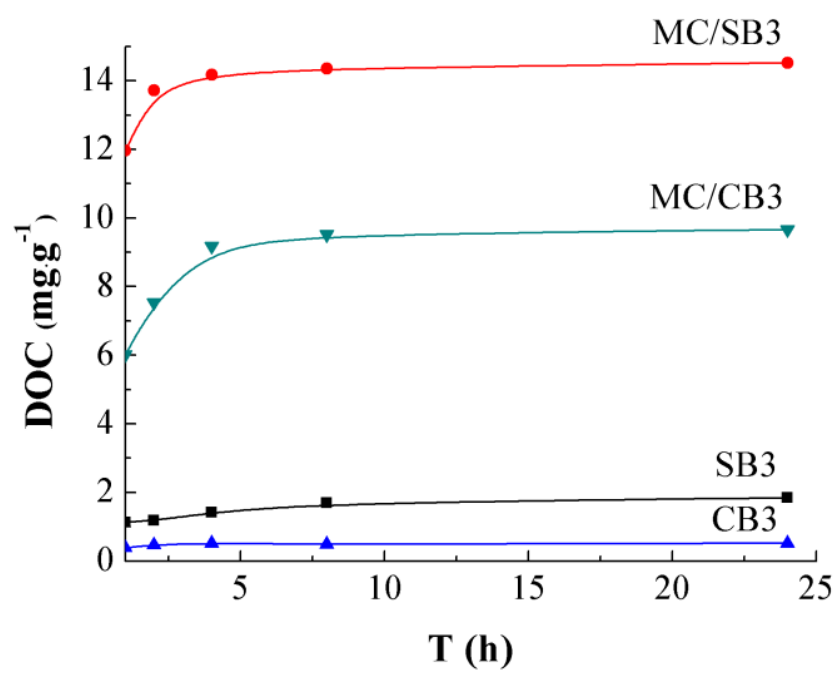

Fig. 2. Release kinetics of DOC from biochar

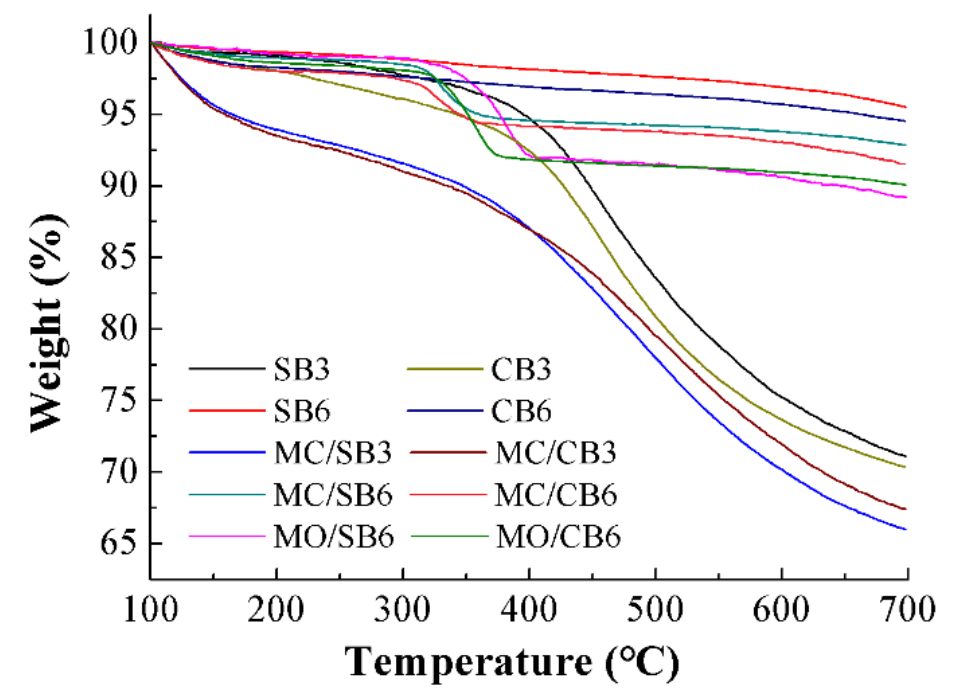

Fig. 3. Curve of TG of biochar

\section{Thermal stability of the resulting biochar}

Thermosgravimetric analysis (TGA) was carried out under a nitrogen atmosphere to evaluate the thermal stability of the biochar (Fig. 3). The biochar pyrolyzed at $300{ }^{\circ} \mathrm{C}$ had a $25 \%$ to $35 \%$ weight loss at temperatures from 100 to $700{ }^{\circ} \mathrm{C}$ (Fig. 3). However, biochar pyrolyzed at $600{ }^{\circ} \mathrm{C}$ only had a $3 \%$ to $10 \%$ weight loss at temperatures from 100 to $700{ }^{\circ} \mathrm{C}$ (Fig. 3). The thermal stabilities of biochar followed the following order: SB6 $>\mathrm{CB} 6>$ $\mathrm{MC} / \mathrm{SB} 6>\mathrm{MC} / \mathrm{CB} 6>\mathrm{MO} / \mathrm{CB} 6>\mathrm{MO} / \mathrm{SB} 6>\mathrm{SB} 3>\mathrm{CB} 3>\mathrm{MC} / \mathrm{CB} 3>\mathrm{MC} / \mathrm{SB} 3$. The results suggested that the thermal stability of biochar improved as the pyrolysis temperature increased. The $\mathrm{MgCl}_{2}$ and $\mathrm{MgO}$ impregnated biochars reduced the thermal stability compared to the pristine biochar. This indicated that the addition of $\mathrm{Mg}$ might increase the surface oxygen functional groups of the resulting biochars. 


\section{Chemical stability of carbon in the resulting biochar}

The loss of $\mathrm{C}$ concentration in biochar via $\mathrm{K}_{2} \mathrm{CrO}_{7}$ oxidation is presented in Fig. 4. The loss of $\mathrm{C}$ concentration in biochars prepared at $300{ }^{\circ} \mathrm{C}$ was significantly greater than those at $600{ }^{\circ} \mathrm{C}$ (Fig. 4). The loss of $\mathrm{C}$ concentration in Mg-impregnated biochar prepared at $300{ }^{\circ} \mathrm{C}(\mathrm{MC} / \mathrm{SB} 3$ and $\mathrm{MC} / \mathrm{CB} 3)$ was significantly greater than those in the pristine biochar (SB3 and CB3) (Fig. 4). These results were consistent with previous reports (Chen et al. 2016) that state that the chemical stability of carbon is enhanced via the increasing pyrolysis temperature. The chemical stability of carbon may be related to releasable concentration of DOC (Fig. 2). For example, MC/SB3 and MC/CB3 had the highest carbon loss and releasable concentrations of DOC. DOC is unstable and easily attacked by $\mathrm{K}_{2} \mathrm{CrO}_{7}$ (Li et al. 2014). Results from the $\mathrm{K}_{2} \mathrm{CrO}_{7}$ oxidation indicated that the pyrolysis temperature was the key factor in the chemical stability of carbon in the biochar, and that the $\mathrm{Mg}$ impregnation enhanced the carbon loss of biochar prepared at low pyrolysis temperature $\left(300{ }^{\circ} \mathrm{C}\right)$.

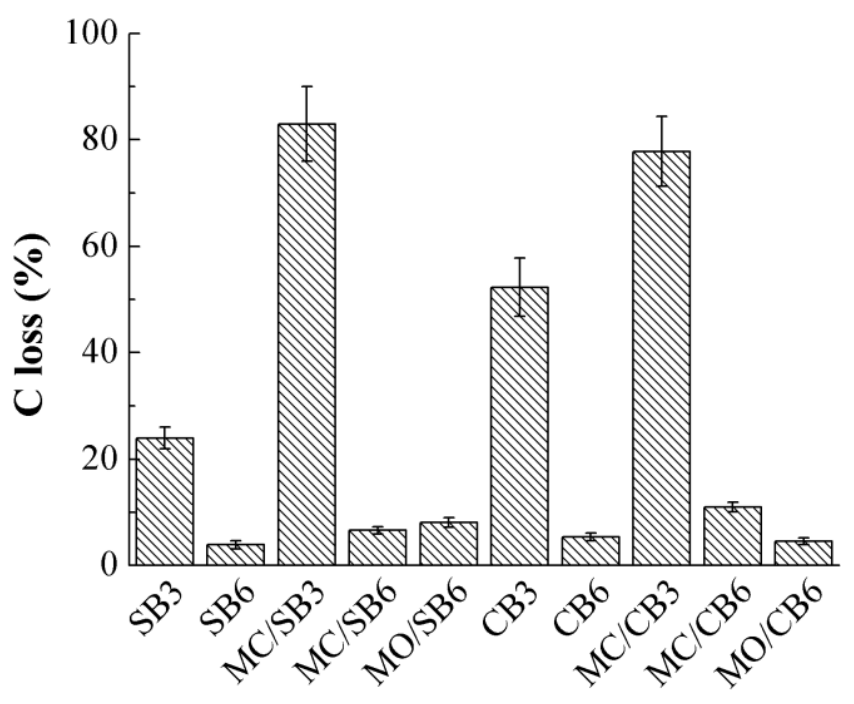

Fig. 4. Carbon loss from biochar through $\mathrm{K}_{2} \mathrm{CrO}_{7}$ oxidation

\section{Sorption Isotherms}

Sorption isotherms of CR and MB onto biochar are shown in Fig. 5. The adsorbed mass of $\mathrm{CR}$ and $\mathrm{MB}$ were increased with the increasing initial concentrations of $\mathrm{CR}$ and $\mathrm{MB}$ and then arrived at an adsorption equilibrium. Figure 5 shows that $\mathrm{Mg}$-impregnation enhanced the sorption of $\mathrm{CR}$ and $\mathrm{MB}$ onto $\mathrm{Mg}$-impregnated biochars significantly compared with the pristine biochars (SB3, SB6, CB3, and CB6). The sorption capacities of Mg-impregnated biochars for $\mathrm{CR}$ were considerably higher than that for $\mathrm{MB}$, and the pristine biochar showed lower sorption capacities for both CR and MB (Fig. 5).

To more aptly evaluate the sorption performance of biochar for $\mathrm{CR}$ and $\mathrm{MB}$, the sorption isothermal data were fitted by using Langmuir and Freundlich isotherm models (Table 2). The coefficients of $\mathrm{R}^{2}$ for the Langmuir model for Mg-impregnated biochar were slightly higher than that for the Freundlich isotherm model, especially in MB sorption, which indicated that the Langmuir and Freundlich isotherm model fitted well with the experimental data. The Freundlich parameter, $1 / n$, can reflect the sorption intensity (Fan et al. 2017). 

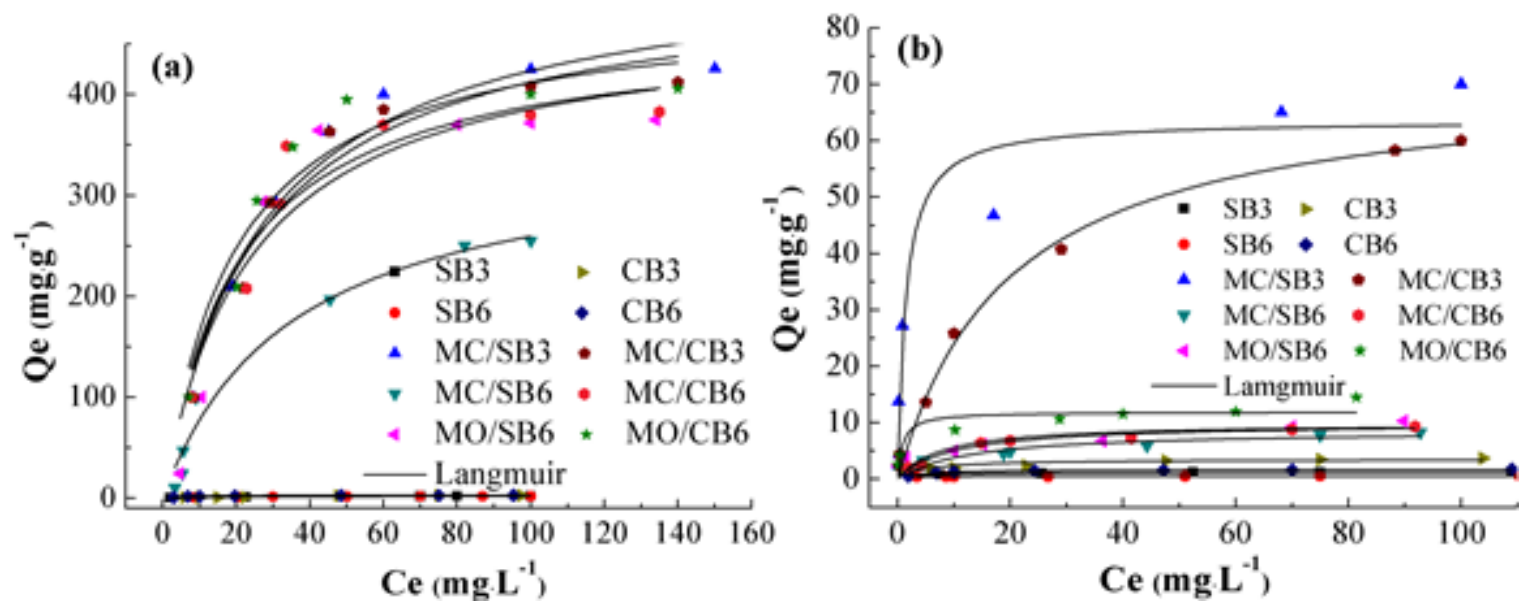

Fig. 5. Sorption isotherm of $C R(a)$ and $M B(b)$ onto biochar

Values of $1 / \mathrm{n}$ were between 0 and 1 for all biochar in this study (Table 2), indicating that the sorption was favorable for $\mathrm{CR}$ and $\mathrm{MB}$. MC/SB3 and $\mathrm{MC} / \mathrm{CB} 3$ exhibited the greatest sorption performance for both $\mathrm{CR}$ and MB. For example, MC/SB3 and MC/CB3 had Langmuir maximum sorption capacities of 534 and $518 \mathrm{mg} \mathrm{g}^{-1}$ for $\mathrm{CR}$, and 63.6 and $71.1 \mathrm{mg} \mathrm{g}^{-1}$ for MB, respectively. The MC/SB6, MO/SB6, MC/CB6, and MO/CB6 showed higher sorption capacities for $\mathrm{CR}$, which were also far higher than that for MB (Table 2). The Langmuir maximum sorption capacities of $\mathrm{MgO}$-pretreated biochars (MO/SB6 and $\mathrm{MO} / \mathrm{CB} 6)$ for both $\mathrm{CR}$ and $\mathrm{MB}$ were higher than that of $\mathrm{MgCl}_{2}$-pretreated biochars (MC/SB6 and MC/CB6). Moreover, the separation factor of the Langmuir model (RL, RL $=1 /\left(1+K_{\mathrm{L}} * C_{0}\right)$, a dimensionless constant, classified the adsorption to be favorable $(0<$ $R L<1)$, unfavorable $(R L>1)$, and linear $(R L=1)$ or irreversible $(R L=0)$. The value of $\mathrm{RL}$ was between 0.02 and 0.34 for $\mathrm{CR}$, and 0.02 and 0.11 for $\mathrm{MB}$, which suggested favorable adsorption for $\mathrm{CR}$ and $\mathrm{MB}$ in biochar.

Different sorption mechanisms were involved in the sorption of $\mathrm{CR}$ and MB. In this study, the pHPZC of biochar (between 7.4 and 10.6) was higher than the experimental solution $\mathrm{pH}$ (around 7); therefore, biochar contained surface positive charges for the favorable sorption of anionic contaminants. Congo red is an anionic dye and $\mathrm{MB}$ is a cationic dye. Therefore, biochar with surface positive charges was favorable for the sorption of $\mathrm{CR}$, and unfavorable for MB. The difference between Langmuir maximum sorption capacities for $\mathrm{CR}$ and $\mathrm{MB}$ suggested that electrostatic interaction may be an important mechanism for CR sorption. Compared with the pristine biochar (SB3, SB6, CB3, and CB6), Mg-impregnation improved the Langmuir maximum sorption capacities of biochars for both $\mathrm{CR}$ and MB. The FT-IR spectra showed that MC/CB3, MC/SB3, $\mathrm{MC} / \mathrm{CB} 3$, and $\mathrm{MC} / \mathrm{SB} 3$ had more abundant surface containing functional groups than $\mathrm{MC} / \mathrm{CB} 6, \mathrm{MC} / \mathrm{SB} 6, \mathrm{MO} / \mathrm{SB} 6$, and MO/CB6 (Fig. 1). It is reported that the groups of $\mathrm{COOH}$ and $-\mathrm{OH}$ have a specific role for dye (Xu et al. 2011). MC/SB3 and MC/CB3 had the greatest sorption capacities for both $\mathrm{CR}$ and $\mathrm{MB}$, suggesting that complexation may be involved in the sorption and hydrophobic interaction and $\circlearrowleft-љ$ interactions may be not important sorption mechanisms of $\mathrm{CR}$ and $\mathrm{MB}$. It can be inferred that electrostatic interaction is the main mechanism for CR sorption, followed by complexation in this study; while complexation is the main mechanism for MB sorption. 
Table 2. Parameters for Sorption of $\mathrm{CR}$ and $\mathrm{MB}$ onto Biochar

\begin{tabular}{|c|c|c|c|c|c|c|c|c|c|c|c|c|}
\hline & \multicolumn{6}{|c|}{ Langmuir $\left(\mathrm{Ce} / \mathrm{Qe}=\mathrm{Ce} / \mathrm{Q} m+1 /\left(\mathrm{Q} m \times K_{L}\right)\right.$} & \multicolumn{6}{|c|}{ Freundlich $\left(\ln Q e=\ln K_{F}+1 / n \times \ln C e\right)$} \\
\hline & \multicolumn{3}{|c|}{ CR } & \multicolumn{3}{|l|}{ MB } & \multicolumn{3}{|c|}{$\mathrm{CR}$} & \multicolumn{3}{|l|}{ MB } \\
\hline & $Q_{\mathrm{m}}$ & $K_{\mathrm{L}}$ & $\mathrm{R}^{2}$ & $Q_{\mathrm{m}}$ & $K_{\mathrm{L}}$ & $\mathrm{R}^{2}$ & $K_{\mathrm{F}}$ & $1 / n$ & $\mathrm{R}^{2}$ & $K_{\mathrm{F}}$ & $1 / n$ & $\mathrm{R}^{2}$ \\
\hline SB3 & 2.67 & 0.042 & 0.90 & 1.25 & 0.266 & 0.89 & 0.31 & 0.426 & 0.94 & 0.54 & 0.191 & 0.89 \\
\hline SB6 & 2.24 & 0.053 & 0.96 & 0.55 & 0.539 & 0.90 & 0.39 & 0.352 & 0.81 & 0.33 & 0.122 & 0.93 \\
\hline $\mathrm{MC} / \mathrm{SB} 3$ & 535 & 0.038 & 0.96 & 63.6 & 0.705 & 0.92 & 80.5 & 0.356 & 0.81 & 19.4 & 0.285 & 0.90 \\
\hline $\mathrm{MC} / \mathrm{SB} 6$ & 351 & 0.029 & 0.97 & 8.59 & 0.080 & 0.84 & 19.4 & 0.574 & 0.94 & 1.70 & 0.346 & 0.81 \\
\hline $\mathrm{MO} / \mathrm{SB} 6$ & 477 & 0.042 & 0.90 & 9.90 & 0.133 & 0.83 & 60.2 & 0.402 & 0.75 & 3.14 & 0.250 & 0.75 \\
\hline CB3 & 4.55 & 0.019 & 0.90 & 3.50 & 0.227 & 0.90 & 0.23 & 0.566 & 0.88 & 1.32 & 0.250 & 0.85 \\
\hline CB6 & 3.01 & 0.169 & 0.98 & 1.75 & 0.268 & 0.99 & 1.02 & 0.238 & 0.89 & 0.73 & 0.197 & 0.86 \\
\hline MC/CB3 & 518 & 0.039 & 0.94 & 71.1 & 0.051 & 0.99 & 78.5 & 0.358 & 0.80 & 8.93 & 0.420 & 0.98 \\
\hline MC/CB6 & 468 & 0.049 & 0.88 & 9.93 & 0.103 & 0.96 & 88.3 & 0.321 & 0.72 & 2.19 & 0.330 & 0.91 \\
\hline MO/CB6 & 493 & 0.051 & 0.91 & 11.9 & 1.223 & 0.82 & 95.4 & 0.315 & 0.73 & 5.05 & 0.227 & 0.81 \\
\hline
\end{tabular}

$C_{e}$ : solution equilibrium concentrations of $\mathrm{MB}$ and $\mathrm{CR}\left(\mathrm{mg} \mathrm{L}^{-1}\right), Q_{e}:$ equilibrium adsorption amount $\left(\mathrm{mg} \mathrm{g}^{-1}\right), Q_{m}$ : maximum sorption capacity of adsorbent (mg $\left.\mathrm{g}^{-1}\right), K_{L}$ : Langmuir constant related to the sorption energy $\left(\mathrm{L} \mathrm{mg}^{-1}\right), K_{F}$ : Freundlich constant $\left(\mathrm{mg}^{1-1 / n} \mathrm{~L}^{1 / n} \mathrm{~g}^{-1}\right)$, and $1 / n$ : intensity of adsorption 


\section{Environmental Implications of Sorption Capacity and Biochar Stability}

The chemical and thermal stability of biochar are important parameters for its environmental application. The chemical stability of biochar was investigated using $\mathrm{K}_{2} \mathrm{CrO}_{7}$ oxidation to show that a higher pyrolysis temperature could enhance its chemical stability, while Mg-impregnation could decrease the chemical stability. This would be especially true for biochar prepared at a low pyrolysis temperature $\left(300^{\circ} \mathrm{C}\right)(\mathrm{Fig} .4)$. The thermal stability was investigated using thermosgravimetric analysis to show that the thermal stability of biochar could be improved by increasing the pyrolysis temperature and that $\mathrm{Mg}$ impregnation could reduce the thermal stability (Fig. 1), which were consistent with the chemical stability. It is reported that higher pyrolysis temperatures remove the low thermal resistance components, increase cyclic oxygen functional groups such as carboxylic anhydrides $\left(460{ }^{\circ} \mathrm{C}\right)$, hydroxyl $\left(570{ }^{\circ} \mathrm{C}\right)$, and lactones $\left(720{ }^{\circ} \mathrm{C}\right)$ with high thermal resistance, and enhance aromaticity of biochar (Tan et al. 2015; Xie et al. 2016). For example, the atomic ratios of $\mathrm{O} / \mathrm{C},(\mathrm{O}+\mathrm{N}) / \mathrm{C}$, and $\mathrm{H} / \mathrm{C}$ are used to reflect the bulk hydrophilicity, polarity, and aromatization of biochar. In this study, The H/C values of biochar under $600{ }^{\circ} \mathrm{C}$ were lower than that in other biochar, indicating that biochar under higher pyrolysis temperature exhibited higher chemical stability (Table 1). The chemical stability of biochar is generally positively related to their thermal stability. Higher ash concentrations decreased the aromatic carbon of biochar, which reduced the stability of carbon in biochar. However, ash content has a positive effect on metal sorption (Guo and Chen 2014). The more oxygen-containing functional groups in the biochar, the weaker the stability of the biochar. But the oxygen-containing functional groups may play an important role in sorption of certain contaminants, owing to surface complexation with contaminants (Inyang et al. 2016). In this study, Mg-impregnation improved their Langmuir maximum sorption capacities of biochar for both $\mathrm{CR}$ and $\mathrm{MB}$, and MC/SB3 and MC/CB3 have the highest sorption capacities for $\mathrm{CR}$ and $\mathrm{MB}$. However, MC/SB3 and MC/CB3 showed a lower chemical and thermal stability. Therefore, the chemical and thermal stability of biochars may be not positively related to their sorption performance. This data suggests that high stability of biochar does not lead to favorable sorption performance.

\section{CONCLUSIONS}

1. $\mathrm{MgCl}_{2}$ and $\mathrm{MgO}$ pretreatment can increase the contents of $\mathrm{Mg}$, yield, $\mathrm{pH} P \mathrm{Pz}$, and ash and decrease the $\mathrm{C}$ contents in the resulting biochar.

2. Magnesium-impregnation decreased the chemical oxidation stability of the resulting biochar at low pyrolysis temperatures $\left(300^{\circ} \mathrm{C}\right)$ compared to the pristine biochar.

3. $\mathrm{MgCl}_{2}$ and $\mathrm{MgO}$ impregnated biochar had high sorption capacities for $\mathrm{CR}$ and $\mathrm{MB}$, but especially for CR because it is an anionic contaminant.

4. Magnesium-impregnation and low pyrolysis temperature are favorable for the preparation of sorbents with high sorption capacities of anionic contaminants.

\section{ACKNOWLEDGMENTS}

This work was supported by the National Natural Science Fund of China (No. $21677075,21507060)$. 


\section{REFERENCES CITED}

Azargohar, R., Jacobson, K. L., Powell, E. E., and Dalai, A. K. (2013). "Evaluation of properties of fast pyrolysis products obtained, from Canadian waste biomass," Journal of Analytical and Applied Pyrolysis 104, 330-340. DOI: 10.1016/j.jaap.2013.06.016

Chen, D. G., Yu, X. Z., Song, C., Pang, X. L., Huang, J., and Li, Y. J. (2016). "Effect of pyrolysis temperature on the chemical oxidation stability of bamboo biochar," Bioresource Technology 218, 1303-1306. DOI: 10.1016/j.biortech.2016.07.112

Fan, S. S., Wang, Y., Wang, Z., Tang, J., Tang, J., and Li, X. D. (2017). "Removal of methylene blue from aqueous solution by sewage sludge-derived biochar: Adsorption kinetics, equilibrium, thermodynamics and mechanism," Journal of Environmental Chemical Engineering 5(1), 601-611. DOI: 10.1016/j.jece.2016.12.019

Gaskin, J. W., Steiner, C., Harris, K., Das, K. C., and Bibens, B. (2008). "Effect of lowtemperature pyrolysis conditions on biochar for agricultural use," Transactions the Asabe 51(6), 2061-2069.

Guo, J. H., and Chen, B. L. (2014). "Insights on the molecular mechanism for the recalcitrance of biochar: interactive effects of carbon and silicon components," Environmental Science \& Technology 48(16), 9103-9112. DOI: 10.1021/es405647e

Hu, X., Ding, Z. H., Zimmerman, A. R., Wang, S. S., and Gao, B. (2015). "Batch and column sorption of arsenic onto iron-impregnated biochar synthesized through hydrolysis," Water Research 68, 206-216. DOI: 10.1016/j.watres.2014.10.009

Inyang, M. I., Gao, B., Yao, Y., Xue, Y. W., Zimmerman, A., Mosa, A., Pullammanappallil, P., Ok, Y. S., and Cao, X. D. (2016). "A review of biochar as a low-cost adsorbent for aqueous heavy metal removal," Critical Reviews in Environmental Science and Technology 46(4), 406-433. DOI: 10.1080/10643389.2015.1096880

Kosmulski, M. (2016). "Isoelectric points and points of zero charge of metal (hydr)oxides: 50 years after Parks' review," Advances in Colloid and Interface Science 238, 1-61. DOI: 10.1016/j.cis.2016.10.005

Li, F. Y., Cao, X. D., Zhao, L., Wang, J. F., and Ding, Z. L. (2014). "Effects of mineral additives on biochar formation: carbon retention, stability, and properties," Environmental Science \& Technology 48(19), 11211-11217. DOI: $10.1021 / \mathrm{es} 5018851$

Li, H. B., Dong, X. L., da Silva, E. B., de Oliveira, L. M., Chen, Y. S., and Ma, L. N. Q. (2017). "Mechanisms of metal sorption by biochar: Biochar characteristics and modifications," Chemosphere 178, 466-478. DOI:

10.1016/j.chemosphere.2017.03.072

Liu, W. J., Jiang, H., Tian, K., Ding, Y. W., and Yu, H. Q. (2013). “Mesoporous carbon stabilized $\mathrm{MgO}$ nanoparticles synthesized by pyrolysis of $\mathrm{MgCl}_{2}$ preloaded waste biomass for highly efficient $\mathrm{CO}_{2}$ capture," Environmental Science \& Technology 47(16), 9397-9403. DOI: 10.1021/es401286p

Li, X., and Cao, Y. Chemical Formula Manual. 1987.12, Science Press, Beijing (in Chinese).

Singh, B. P., Cowie, A. L., and Smernik, R. J. (2012). "Biochar carbon stability in a clayey soil as a function of feedstock and pyrolysis temperature," Environmental Science \& Technology 46(21), 11770-11778. DOI: 10.1021/es302545b

Tan, X. F., Liu, Y. G., Zeng, G. M., Wang, X., Hu, X. J., Gu, Y. L., and Yang, Z. Z. 
(2015). "Application of biochar for the removal of pollutants from aqueous solutions," Chemosphere 125, 70-85. DOI: 10.1016/j.chemosphere.2014.12.058

Xie, T., Sadasivam, B. Y., Reddy, K. R., Wang, C. W., and Spokas, K. (2016). "Review of the effects of biochar amendment on soil properties and carbon sequestration," Journal of Hazardous Toxic and Radioactive Waste 20(1). DOI: 10.1061/(ASCE)HZ.2153-5515.0000293

Xu, K. N., Lin, F. Y., Dou, X. M., Zheng, M., Tan, W., and Wang, C. W. (2018). "Recovery of ammonium and phosphate from urine as value-added fertilizer using wood waste biochar loaded with magnesium oxides," Journal of Cleaner Production 187, 205-214. DOI: 10.1016/j.jclepro.2018.03.206

Xu, R. K., Xiao, S. C., Yuan, J. H., and Zhao, A. Z. (2011). "Adsorption of methyl violet from aqueous solutions by the biochar derived from crop residues," Bioresource Technology 102(22), 10293-10298. DOI: 10.1016/j.biortech.2011.08.089

Xu, X. B., Hu, X., Ding, Z. H., and Chen, Y. J. (2017). "Effects of copyrolysis of sludge with calcium carbonate and calcium hydrogen phosphate on chemical stability of carbon and release of toxic elements in the resultant biochar," Chemosphere 189, 7685. DOI: 10.1016/j.chemosphere.2017.09.021

Zhao, L., Cao, X. D., Zheng, W., Wang, Q., and Yang, F. (2015). "Endogenous minerals have influences on surface electrochemistry and ion exchange properties of biochar," Chemosphere 136, 133-139. DOI: 10.1016/j.chemosphere.2015.04.053

Article submitted: July 14, 2018; Peer review completed: October 11, 2018; Revised version received and accepted: November 1, 2018; Published: November 16, 2018. DOI: 10.15376/biores.14.1.289-301 